\title{
Expansion of CD16-Negative Natural Killer Cells in the Peripheral Blood of Patients with Metastatic Melanoma
}

\author{
Shernan G. Holtan, ${ }^{1,2}$ Douglas J. Creedon, ${ }^{3}$ Michael A. Thompson, ${ }^{4}$ Wendy K. Nevala, ${ }^{4}$ \\ and Svetomir N. Markovic ${ }^{1,2,4}$ \\ ${ }^{1}$ Division of Hematology, Department of Medicine, Mayo Clinic Graduate School of Medicine, 200 First Street SW, \\ Rochester, MN 55905, USA \\ ${ }^{2}$ Department of Oncology, Mayo Clinic Graduate School of Medicine, 200 First Street SW, Rochester, MN 55905, USA \\ ${ }^{3}$ Department of Obstetrics and Gynecology, Mayo Clinic Graduate School of Medicine, 200 First Street SW, \\ Rochester, MN 55905, USA \\ ${ }^{4}$ Department of Immunology, Mayo Clinic Graduate School of Medicine, 200 First Street SW, Rochester, MN 55905, USA
}

Correspondence should be addressed to Svetomir N. Markovic, markovic.svetomir@mayo.edu

Received 14 October 2010; Revised 17 December 2010; Accepted 17 January 2011

Academic Editor: Ronald Herberman

Copyright (C) 2011 Shernan G. Holtan et al. This is an open access article distributed under the Creative Commons Attribution License, which permits unrestricted use, distribution, and reproduction in any medium, provided the original work is properly cited.

\begin{abstract}
Altered natural killer (NK) cell function is a component of the global immune dysregulation that occurs in advanced malignancies. Another condition associated with altered NK homeostasis is normal pregnancy, where robust infiltration with CD16- CD9+ NK cells can be identified in decidual tissues, along with a concomitant expansion of CD16- NK cells in the maternal peripheral blood. In metastatic melanoma, we identified a similar expansion of peripheral blood CD16- NK cells (median $7.4 \%$ in 41 patients with melanoma compared with $3.0 \%$ in 29 controls, $P<.001$ ). A subset of NK cells in melanoma patients also expresses CD9, which is characteristically expressed only on NK cells within the female reproductive tract. Expansion of CD16- NK cells was associated with elevated plasma transforming growth factor-beta (TGF- $\beta$ levels (median $20 \mathrm{ng} / \mathrm{ml}$, Spearman's $\rho=0.81, P=.015$ )). These findings suggest the possibility of exploring anti-TGF- $\beta$ therapy to restore NK function in melanoma.
\end{abstract}

\section{Introduction}

Natural killer (NK) cells are a critical component of innate immunity and tumor immunosurveillance in melanoma and other malignancies [1]. Impairment of NK cytolytic function has previously been described in melanoma $[2,3]$. Another physiologic condition associated with a shift in NK homeostasis toward a noncytolytic phenotype is normal human pregnancy, where expansion of weakly cytotoxic CD56bright CD16dim/- NK cells (hereafter referred to as CD16- NK cells to distinguish from CD56bright NK cells, which may represent predecessors to CD16+ mature NK cells [4]) can be seen both in the peripheral blood [5] of pregnant women and enriched at the fetomaternal interface [6]. Specialized decidual NK cells at the fetomaternal interface serve an immunoregulatory/angiogenic function to support placentation and are phenotypically identified by the expression of CD9, a tetraspanin involved in cell adhesion [7]. Mature peripheral blood CD16+ NK cells can be transformed into CD16- CD9+ NK cells with a decidual phenotype after prolonged exposure to transforming growth factor-beta (TGF- $\beta$ [8], a cytokine with pleiotropic immunologic effects including potential regulation of NK function at the host/tumor interface [9].) Here, we test the hypothesis that CD16- NK cells are expanded in the peripheral blood of melanoma patients as previously described in normal pregnancy. Additionally, we assessed CD9 expression on peripheral blood NK cells and determined the presence of an association with elevated TGF- $\beta$ levels in patients with metastatic melanoma.

\section{Materials and Methods}

2.1. Collection of Patient Biospecimens. NK subset analysis was performed on the peripheral blood of 41 patients with 
untreated metastatic melanoma, 39 of whom had plasma available for multiplex cytokine arrays. For comparison, NK subsets were also analyzed in 29 healthy control individuals. Samples from patients with metastatic melanoma (newly diagnosed, previously untreated) as well as healthy volunteers/controls were collected under separate specimen banking protocols. Both protocols were reviewed and approved by the Mayo Clinic Institutional Review Board for use in these studies. Written informed consent was obtained from participants for banking of blood and tissue samples, and Mayo Clinic IRB approvals were granted for the specific studies detailed in this work. Peripheral venous blood (50-90 mL) was drawn into heparinized Vacutainer tubes that were processed and separated into plasma and peripheral blood mononuclear cells (PBMCs) following gradient centrifugation using Ficoll-Paque (GE Healthcare, Uppsala, Sweden). Plasma was collected and immediately frozen at $-80^{\circ} \mathrm{C}$ in $1 \mathrm{~mL}$ aliquots. The PBMCs were collected, washed in phosphate buffered saline, counted, diluted to $1 \times 10^{7} / \mathrm{mL}$, and viably frozen in $90 \%$ cosmic calf serum (Hyclone Inc., Logan, UT) and 10\% dimethylsulfoxide (Sigma, St. Louis, MO).

\subsection{Evaluation of NK Cell Subsets by Flow Cytometry.} Previously frozen PBMCs $\left(0.5-1.0 \times 10^{6}\right.$ cells $\left./ \mathrm{mL}\right)$ from patients with metastatic melanoma as well as healthy control patients were used for determination of NK cell subsets. Four-color flow cytometry was performed using an LSRII flow cytometer (Becton Dickinson), and CellQuest software (Becton Dickinson, San Jose, CA) was used for data analysis. The following anti-human monoclonal antibodies were used in PBMC immunophenotyping for flow cytometry: antiCD3-PE-Cy5, anti-CD56-phycoerythrin, anti-CD16-Alexa Fluor 647, and anti-CD9 fluorescein isothiocyanate (BD Pharmingen).

2.3. Plasma Cytokine, Chemokine, and Growth Factor Concentrations. Protein levels for cytokines, chemokines, and growth factors, including IL- $1 \beta$, IL-1ra, IL-2, IL-4, IL-5, IL6, IL-7, IL-8, IL-10, IL-12p70, IL-13, IL-15, IL-17, G-CSF, GM-CSF, IFN- $\gamma$, IP-10, MCP-1, MIP- $1 \alpha$, MIP- $1 \beta$, TNF- $\alpha$, and VEGF, were measured using either the Bio-Plex cytokine assay (Bio-Rad, Hercules, CA, 28 patients) or Invitrogen BioSource multiplex cytokine assay (Invitrogen Corporation, Carlsbad, CA, 11 patients) as per manufacturer's instructions. Briefly, patient plasma was diluted $1: 4$ in dilution buffer and $50 \mu \mathrm{L}$ was added to washed, fluorescently dyed microspheres (beads) to which biomolecules of interest are bound. The beads and diluted patient plasma were incubated for 30 minutes at room temperature with agitation. After the incubation, the beads were washed in wash buffer and placed in $25 \mu \mathrm{L}$ of detection antibody and incubated for 30 minutes as described above. After washing, the beads were placed in streptavidin-phycoerythrin, incubated, and washed a final time. The bound beads were resuspended in 125 microliters of assay buffer and read with the Luminex plate reader (Bio-Rad, Hercules, CA). Protein concentrations were determined using a standard curve generated using the high PMT concentrations with sensitivity from $10-1000 \mathrm{pg} / \mathrm{mL}$.

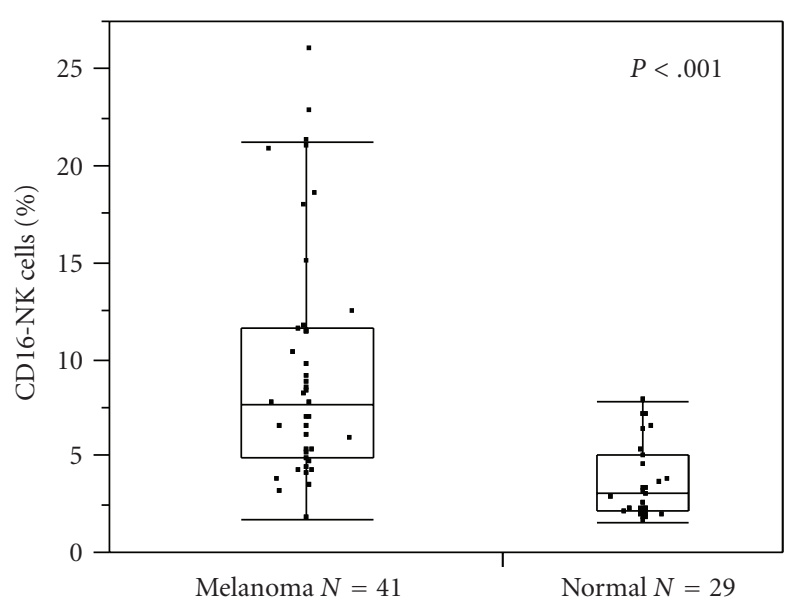

FIgURE 1: Patients with metastatic melanoma have expanded peripheral blood CD16- NK cell pools. Box-plot with quartiles depicting percentage of CD16- NK cells in peripheral blood from 41 metastatic melanoma patients (median 7.6\%) compared with 29 healthy controls (median 3.1\%, Mann-Whitney $P<.001$ ).

2.4. Determination of Plasma TGF- $\beta$ Levels by ELISA. Plasma levels of TGF- $\beta 1$ were determined by ELISA using a duoset antibody pair (R\&D Systems, Minneapolis, MN) as per manufacturer's instructions.

2.5. Statistical Analysis. Differences in percentage of peripheral blood CD16- NK cells between healthy subjects and patients with metastatic melanoma were determined by the Mann-Whitney U test. Correlations between TGF- $\beta$ levels and the percentage of NK cell subsets ware determined by Spearman's $\rho$. Correlations between cytokines were estimated by the pairwise method.

\section{Results and Discussion}

Circulating CD16- NK cells were expanded 2.5-fold in patients with melanoma compared with healthy controls (Figure 1, median $7.4 \%$ compared with $3.0 \%, P<.001$ ). The Median CD16+ NK cell count was $0.56 \times 10^{9}$ per liter (range $0.03-1.53 \times 10^{9}$ per liter), and the median CD16- NK cell count was $0.11 \times 10^{9}$ per liter (range $0.01-0.50 \times 10^{9}$ per liter) in patients with metastatic melanoma, within range of published values for NK cells in healthy adults [10]. None of the tested multiplex plasma cytokines or growth factors correlated strongly with the distribution of NK cells subsets (Figure 2). Median and range of these parameters are listed in Table 1.

Normal peripheral blood CD16+ NK cells incubated in culture with TGF- $\beta$ result in a transition to a CD16CD9+ phenotype resembling decidual NK cells [8]. Since, like pregnancy [11], metastatic melanoma is a condition associated with elevated TGF- $\beta$ levels [12], we next sought to evaluate whether NK cells in the peripheral blood of patients with metastatic melanoma might also express CD9 or exhibit any subset correlation with plasma levels of TGF$\beta$. Eight untreated melanoma patients had 14 unique samples 


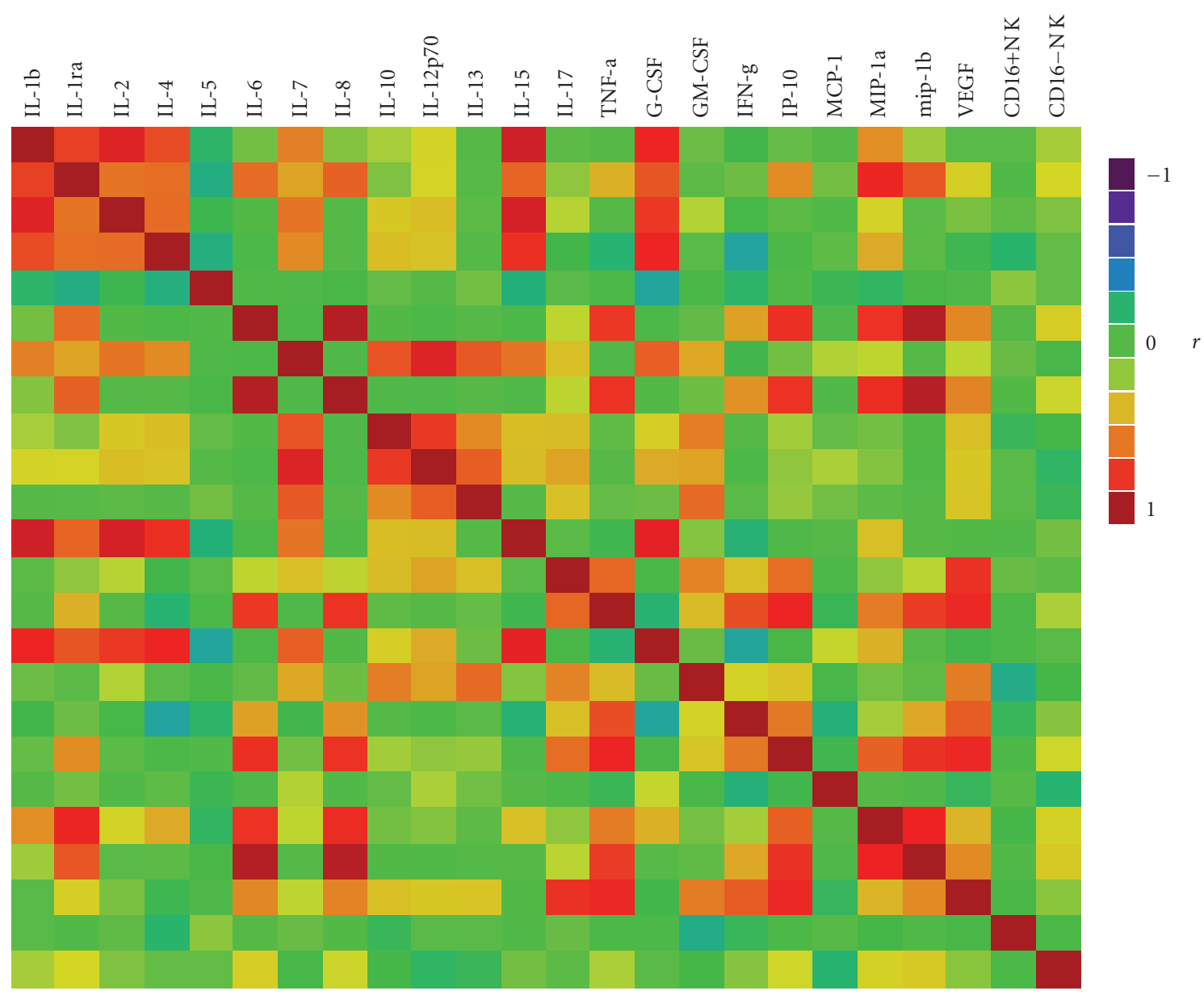

FIGURE 2: Color map on pairwise correlations between NK subsets and plasma cytokines and growth factors. None of the tested multiplex cytokines or growth factors were strongly associated with the percentages of CD16+ or CD16- NK cells.

of PBMCs available for further phenotypic NK testing with CD9 and corresponding plasma for TGF- $\beta$ determination. Representative plots from the experiments demonstrating CD16- CD9+ NK cells in the peripheral blood of metastatic melanoma patients are shown in Figure 3. CD9 was expressed on a median of $24 \%$ of peripheral blood NK cells in patients with metastatic melanoma (Figure 3, range 13.4-37.9\%). This alteration in NK homeostasis toward a CD16- phenotype was strongly correlated with plasma levels of TGF- $\beta$ in these patients (Figure $4(\mathrm{a})$, median $20 \mathrm{ng} / \mathrm{ml}$, Spearman's $\rho=0.81, P=.015)$. A moderate correlation between CD16- CD9+ NK cells and TGF- $\beta$ was observed that did not meet statistical significance (Figure 4(b), Spearman's $\rho=0.48, P=.23$ ).

Bias of NK subsets toward a less cytotoxic and more immunoregulatory phenotype may be a reflection of an overall immunosuppressive milieu in patients with advanced malignancies. The association of expanded CD16- NK cells with elevated TGF- $\beta$ levels has also been identified in patients with esophageal squamous cell carcinoma [13] and gastric cancer [14]. Other examples of altered NK homeostasis in cancer exist, including relative expansion of weakly cytolytic CD16- NK cells in patients with hepatocellular carcinoma compared with healthy controls [15], in the peripheral blood and peritoneal fluid of ovarian cancer patients [16], and in the stroma of nonsmall-cell lung cancer primary tumors [17]. Our results suggest that CD16-CD9+ NK cells may not be specific for the female reproductive tract as once thought, but may instead be reflective of systemic immunomodulation that occurs in melanoma and potentially other conditions associated with high levels of TGF- $\beta$. Our findings will require validation but preliminarily support further investigation into anti-TGF- $\beta$ therapy as a part of cancer immunotherapy.

Recent reports have begun to elucidate the mechanisms by which TGF- $\beta$ suppresses NK function. The NK cell activating receptor NKG2D has recently been described as downregulated by TGF- $\beta$ in cancer patients [18]. Additionally, in the presence of TGF- $\beta$ NK, cells stimulated through CD16 show reduced $T$-BET expression and diminished production of interferon-gamma and tumor necrosis factor-alpha, further demonstrating the suppressive effects of TGF- $\beta$ on NK cells. In melanoma, we have shown that chemotherapeutic intervention with bevacizumab, carboplatin, and paclitaxel can at least transiently alter an individuals' immunologic response to the tumor [19]. However, most patients with 


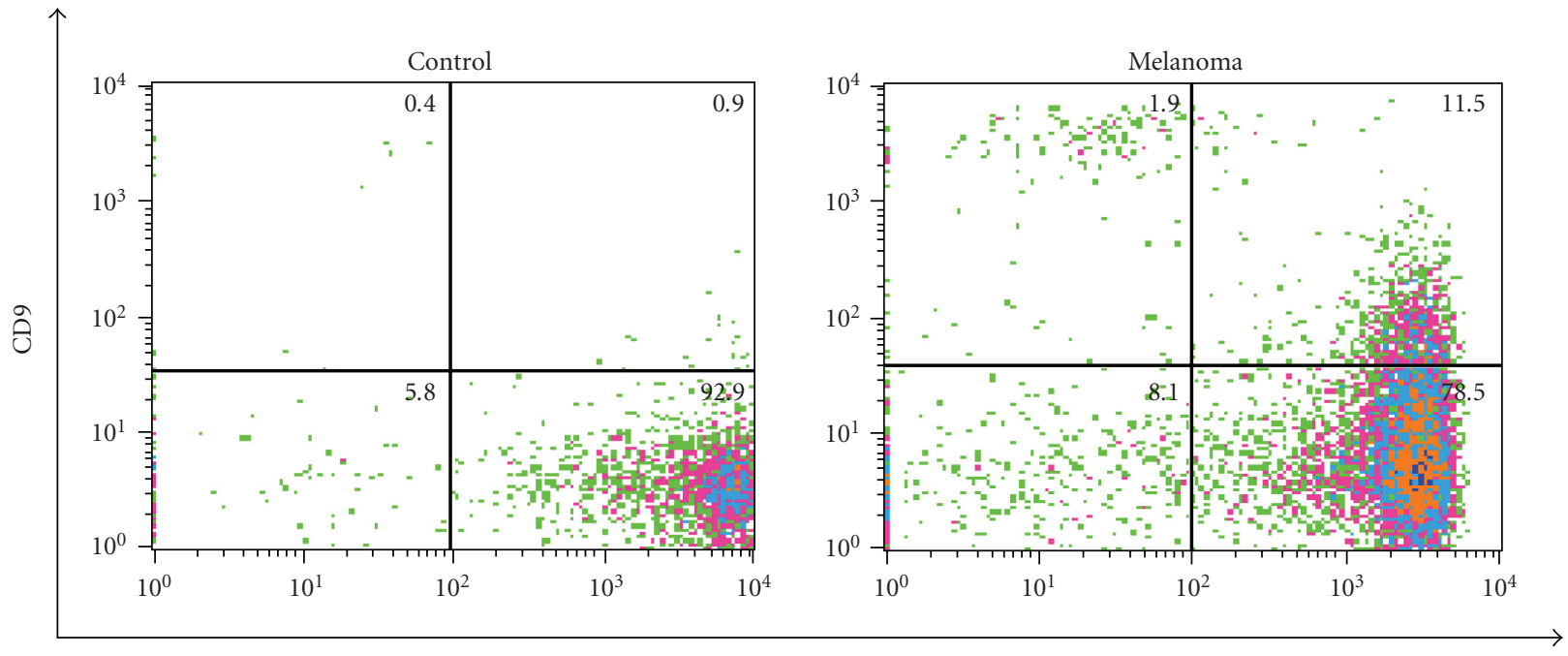

\section{CD16}

FIGURE 3: CD9 expression on NK cells in patients with melanoma. Scatterplot demonstrating CD9 expression in a subset of peripheral blood CD16- NK cells from patients with metastatic melanoma (right). CD9, a marker specific for decidual NK cells is, absent on NK cells from healthy individuals (left). Gating is set on CD3- CD56+ lymphocytes. Numbers represent percentages of total NK cells in each quadrant.

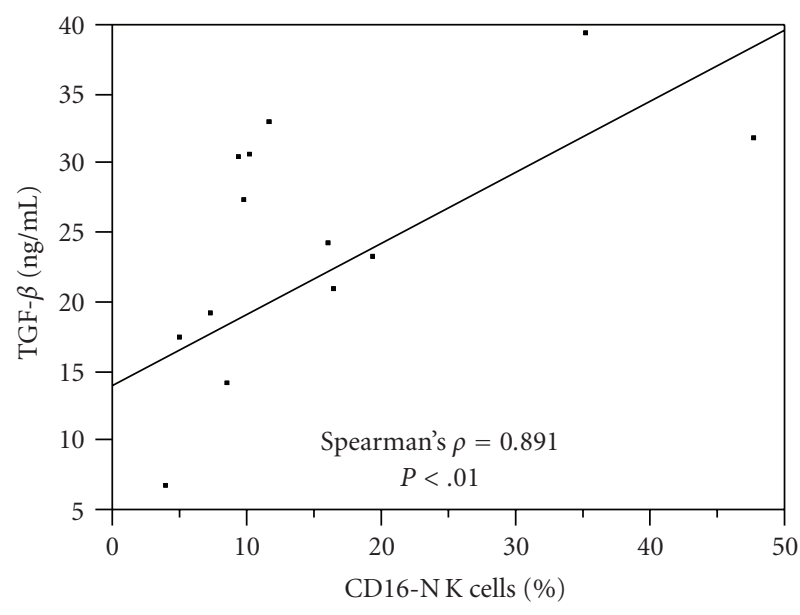

(a)

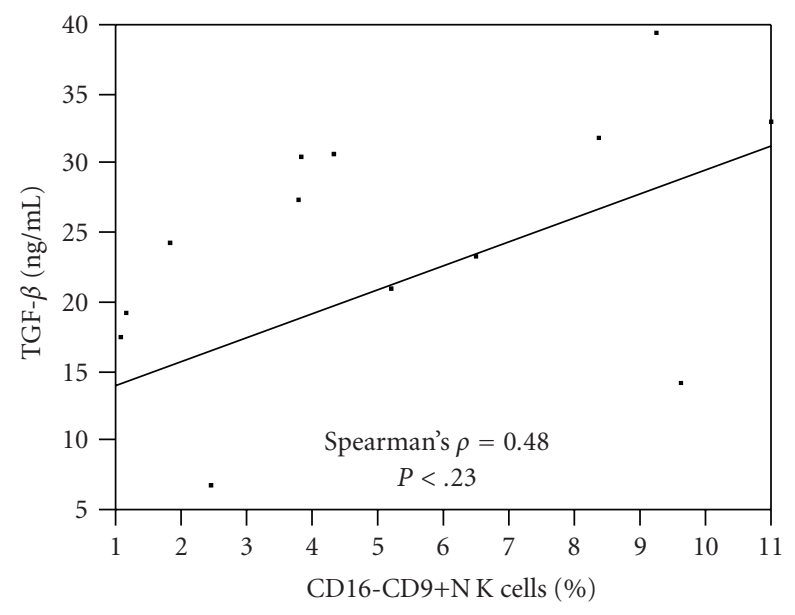

(b)

FIGURE 4: Correlation of TGF- $\beta$ with (a) the CD16- NK cell subset and (b) the CD16- CD9+ subset. Expansion of the CD16- phenotype NK cell subset was strongly correlated with plasma levels of TGF- $\beta$ in these patients. A moderate correlation between CD16- CD9+ NK cells and TGF- $\beta$ did not meet statistical significance.

metastatic melanoma eventually succumb to complications of the cancer that involve systemic dysregulation of immunity, which appears to be manifest in part by altered NK cell homeostasis. In future studies, we will determine whether the observed alteration in NK homeostasis is prognostic or predictive of treatment response and survival in metastatic melanoma.

\section{Conclusion}

Our results suggest that identification and modulation of an immunosuppressive cytokine milieu, for example, high plasma levels of TGF- $\beta$ might allow for restoration of endogenous antitumor immunity, including recovery of NK cytolytic function, and ultimately improve outcomes of melanoma therapy.

\section{Authors' Contributions}

Shernan G. Holtan and Douglas J. Creedon designed the research and wrote the paper, Shernan G. Holtan and Wendy K. Nevala performed experiments and analyzed data, Michael A. Thompson processed and stored cell and plasma specimens, and Svetomir N. Markovic supervised the research and edited the paper. 
TABLE 1: Absolute NK cells counts and plasma cytokine/growth factor levels in patients with metastatic melanoma. Cell counts are measured in cells $\times 10^{9}$ per liter, and plasma cytokines/growth factors are measured in picograms/milliliter.

\begin{tabular}{|c|c|c|c|}
\hline & Median & Minimum & Maximum \\
\hline Absolute NK cell count & 0.64 & 0.13 & 1.66 \\
\hline Absolute CD16+ NK & 0.56 & 0.03 & 1.53 \\
\hline Absolute CD16- NK & 0.11 & 0.01 & 0.50 \\
\hline IL-1b & 3.22 & 0.00 & 1216.46 \\
\hline IL-1ra & 80.90 & 0.19 & 4130.51 \\
\hline IL-2 & 7.42 & 0.00 & 463.38 \\
\hline IL-4 & 3.95 & 0.00 & 129.84 \\
\hline IL-5 & 1.02 & 0.00 & 17.22 \\
\hline IL-6 & 11.83 & 0.41 & 2307.25 \\
\hline IL-7 & 5.38 & 0.58 & 250.24 \\
\hline IL-8 & 11.45 & 0.06 & 2439.86 \\
\hline IL-10 & 4.22 & 0.00 & 175.74 \\
\hline IL-12p70 & 6.88 & 0.00 & 1637.86 \\
\hline IL-13 & 6.07 & 0.00 & 162.68 \\
\hline IL-15 & 9.22 & 0.00 & 709.06 \\
\hline IL-17 & 6.36 & 0.00 & 96.60 \\
\hline TNF- $\alpha$ & 13.28 & 0.00 & 439.51 \\
\hline G-CSF & 16.22 & 0.42 & 622.01 \\
\hline GM-CSF & 70.58 & 0.00 & 419.91 \\
\hline IFN- $\gamma$ & 8.85 & 0.00 & 325.81 \\
\hline IP-10 & 77.56 & 0.73 & 3679.56 \\
\hline MCP-1 & 46.28 & 0.02 & 19679.10 \\
\hline MIP-1a & 8.11 & 0.00 & 907.85 \\
\hline MIP-1b & 79.34 & 0.27 & 13000.21 \\
\hline VEGF & 15.32 & 0.00 & 161.15 \\
\hline
\end{tabular}

\section{Conflict of Interests}

The authors declare no competing financial interests.

\section{References}

[1] I. Waldhauer and A. Steinle, "NK cells and cancer immunosurveillance," Oncogene, vol. 27, no. 45, pp. 5932-5943, 2008.

[2] P. Hersey, A. Edwards, M. Honeyman, and W. H. McCarthy, "Low natural killer cell activity in familial melanoma patients and their relatives," British Journal of Cancer, vol. 40, no. 1, pp. 113-122, 1979.

[3] V. Jović, G. Konjević, S. Radulović, S. Jelić, and I. Spuzić, "Impaired perforin-dependent NK cell cytotoxicity and proliferative activity of peripheral blood T cells is associated with metastatic melanoma," Tumori, vol. 87, no. 5, pp. 324-329, 2001.

[4] C. Romagnani, K. Juelke, M. Falco et al., "CD56CD16 killer Ig-like receptor NK cells display longer telomeres and acquire features of CD56 NK cells upon activation," Journal of Immunology, vol. 178, no. 8, pp. 4947-4955, 2007.
[5] D. Rukavina, E. R. Podack, G. Rubesa, S. Suzana-Pandelo, and L. Randic, "Down-regulated expression of perforinpositive/CD16 cells in the peripheral blood lymphocytes in the first trimester of pregnancy and up-regulation at the end of pregnancy," American Journal of Reproductive Immunology, vol. 38, no. 3, pp. 189-196, 1997.

[6] A. Moffett-King, "Natural killer cells and pregnancy," Nature Reviews Immunology, vol. 2, no. 9, pp. 656-663, 2002.

[7] L. A. Koopman, H. D. Kopcow, B. Rybalov et al., "Human decidual natural killer cells are a unique NK cell subset with immunomodulatory potential," Journal of Experimental Medicine, vol. 198, no. 8, pp. 1201-1212, 2003.

[8] D. B. Keskin, D. S. J. Allan, B. Rybalov et al., "TGF $\beta$ promotes conversion of CD16 peripheral blood NK cells into CD16 NK cells with similarities to decidual NK cells," Proceedings of the National Academy of Sciences of the United States of America, vol. 104, no. 9, pp. 3378-3383, 2007.

[9] L. Yang, Y. Pang, and H. L. Moses, “TGF- $\beta$ and immune cells: an important regulatory axis in the tumor microenvironment and progression," Trends in Immunology, vol. 31, no. 6, pp. 220-227, 2010.

[10] W. J. Chng, G. B. Tan, and P. Kuperan, "Establishment of adult peripheral blood lymphocyte subset reference range for an asian population by single-platform flow cytometry: influence of age, sex, and race and comparison with other published studies," Clinical and Diagnostic Laboratory Immunology, vol. 11, no. 1, pp. 168-173, 2004.

[11] M. C. Lygnos, K. I. Pappa, H. A. Papadaki et al., "Changes in maternal plasma levels of VEGF, bFGF,TGF- $\beta$, ET-1 and sKL during uncomplicated pregnancy, hypertensive pregnancy and gestational diabetes," In Vivo, vol. 20, no. 1, pp. 157-163, 2006.

[12] K. Krasagakis, D. Thölke, B. Farthmann, J. Eberle, U. Mansmann, and C. E. Orfanos, "Elevated plasma levels of transforming growth factor (TGF)- $\beta 1$ and TGF- $\beta 2$ in patients with disseminated malignant melanoma," British Journal of Cancer, vol. 77, no. 9, pp. 1492-1494, 1998.

[13] M. Watanabe, K. Kono, Y. Kawaguchi et al., "NK cell dysfunction with down-regulated CD16 and up-regulated CD56 molecules in patients with esophageal squamous cell carcinoma," Diseases of the Esophagus, vol. 23, no. 8, pp. 675681, 2010.

[14] A. Szkaradkiewicz, T. M. Karpiński, M. Drews, M. BorejszaWysocki, P. Majewski, and E. Andrzejewska, "Natural killer cell cytotoxicity and immunosuppressive cytokines (IL10 , TGF- $\beta 1$ ) in patients with gastric cancer," Journal of Biomedicine and Biotechnology, vol. 2010, Article ID 901564, 2010.

[15] L. Zhou et al., "Characteristics of peripheral NK cells in hepatocellular carcinomar patients," Zhonghua Gan Zang Bing Za Zhi, vol. 18, no. 2, pp. 136-139, 1999.

[16] J. A. Belisle, J. A. A. Gubbels, C. A. Raphael et al., "Peritoneal natural killer cells from epithelial ovarian cancer patients show an altered phenotype and bind to the tumour marker MUC16 (CA125)," Immunology, vol. 122, no. 3, pp. 418-429, 2007.

[17] P. Carrega, B. Morandi, R. Costa et al., "Natural killer cells infiltrating human nonsmall-cell lung cancer are enriched in CD56brightCD16- cells and display an impaired capability to kill tumor cells," Cancer, vol. 112, no. 4, pp. 863-875, 2008. 
[18] J. C. Lee, K. M. Lee, D. W. Kim, and D. S. Heo, "Elevated TGF- $\beta 1$ secretion and down-modulation of NKG2D underlies impaired NK cytotoxicity in cancer patients," Journal of Immunology, vol. 172, no. 12, pp. 7335-7340, 2004.

[19] D. G. Perez, V. J. Suman, T. R. Fitch et al., "Phase 2 trial of carboplatin, weekly paclitaxel, and biweekly bevacizumab in patients with unresectable stage IV melanoma: a North Central Cancer Treatment Group study, N047A," Cancer, vol. 115, no. 1, pp. 119-127, 2009. 


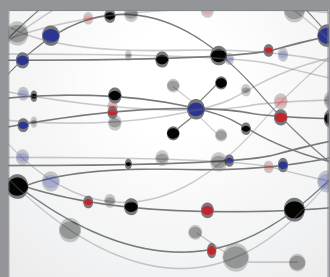

The Scientific World Journal
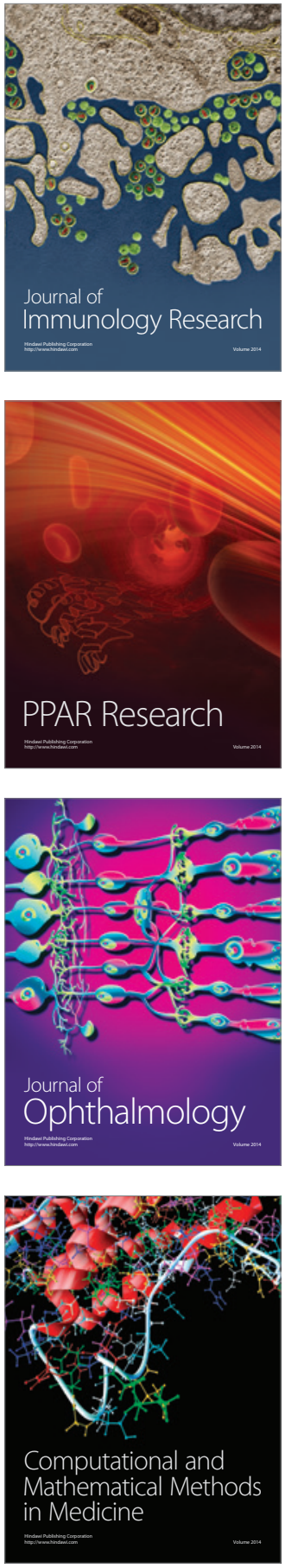

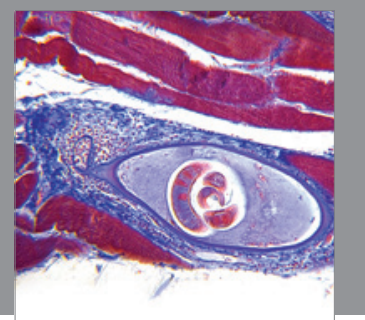

Gastroenterology

Research and Practice
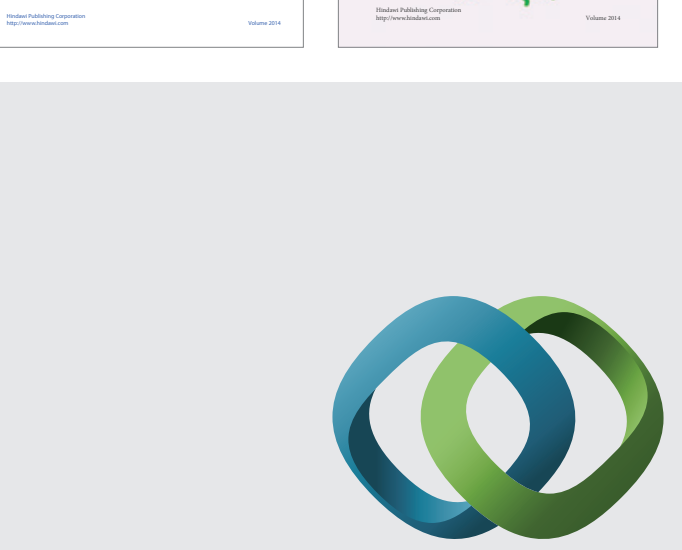

\section{Hindawi}

Submit your manuscripts at

http://www.hindawi.com
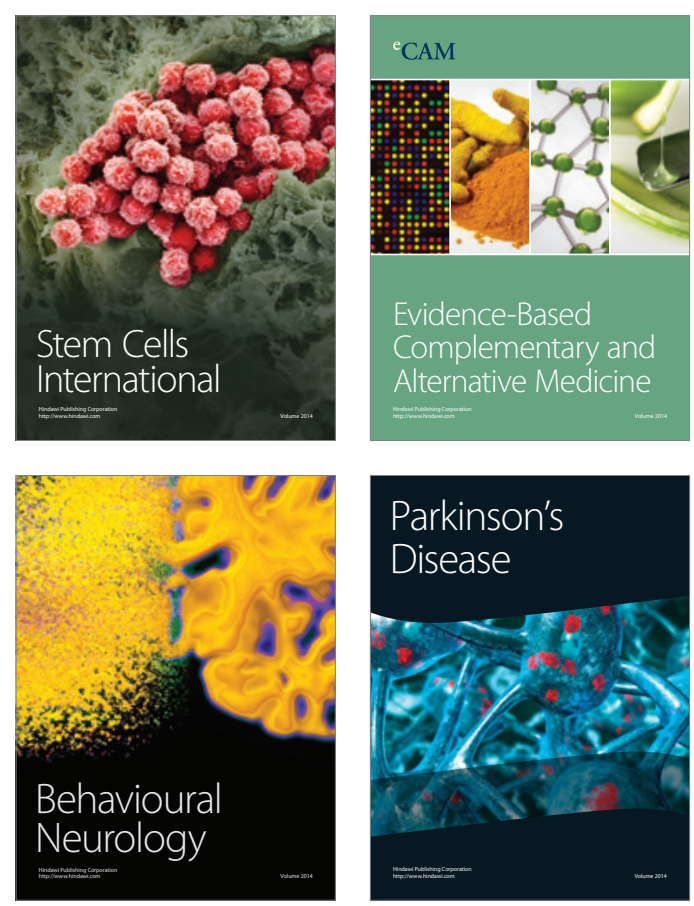

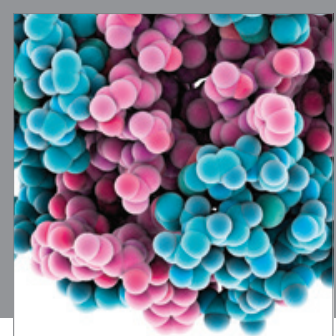

Journal of
Diabetes Research

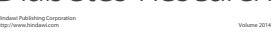

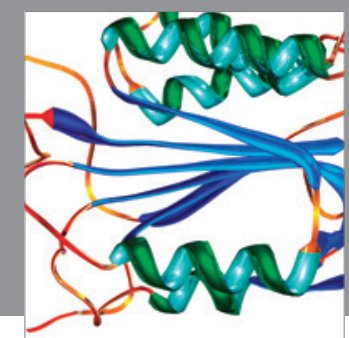

Disease Markers
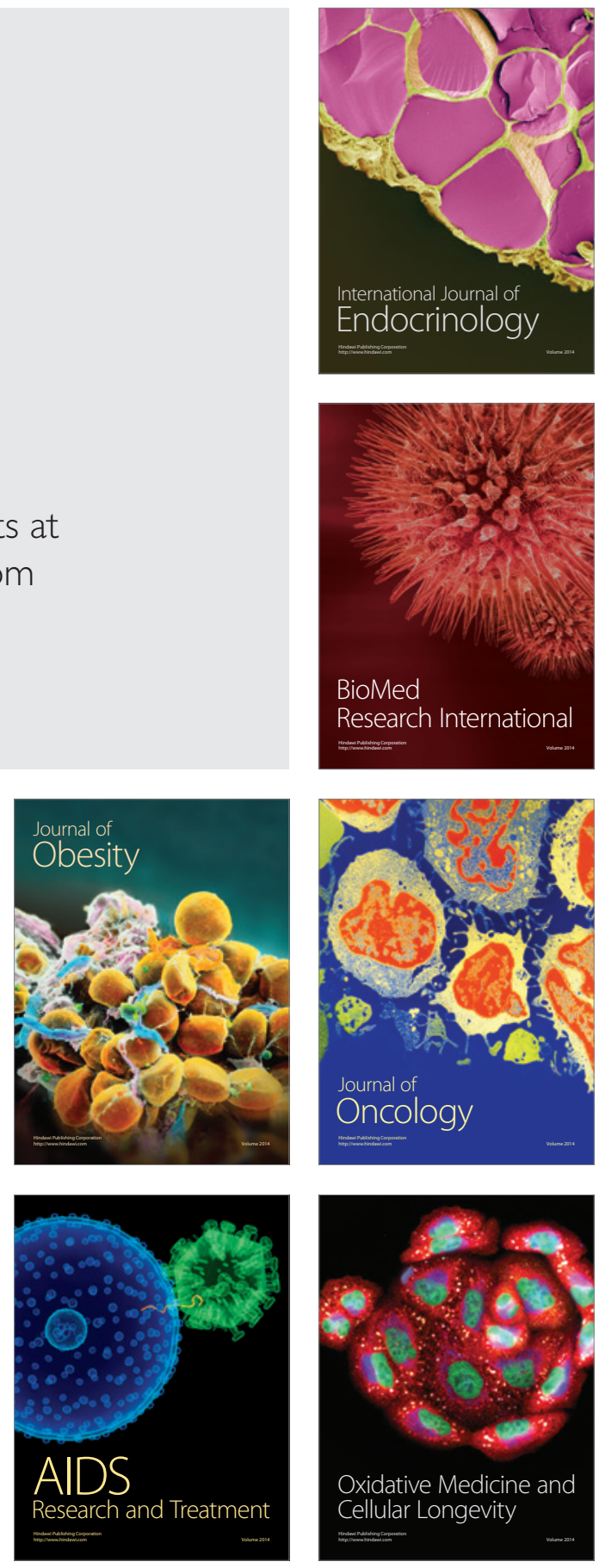